\title{
Nomogram for Predicting Postoperative Cancer- specific Early Death in Patients with Epithelial Ovarian Cancer based on the SEER Database: A Large Cohort Study
}

\section{Tingting Zhang}

Shengjing Hospital of China Medical University, Liancheng Zhu ( $\nabla$ medecin@126.com )

Shengjing Hospital of China Medical University https://orcid.org/0000-0002-0814-5816

\section{Research Article}

Keywords: Ovarian cancer, nomogram, prognosis, cancer-specific survival, early death, SEER

Posted Date: September 13th, 2021

DOl: https://doi.org/10.21203/rs.3.rs-632075/v1

License: (c) (i) This work is licensed under a Creative Commons Attribution 4.0 International License. Read Full License

Version of Record: A version of this preprint was published at Archives of Gynecology and Obstetrics on November 29th, 2021. See the published version at https://doi.org/10.1007/s00404-021-06342-x. 


\section{Abstract}

Background: Ovarian cancer is a common gynecological malignant tumor. Poor prognosis is strongly associated with early death, but there is no effective tool to predict this. This study aimed to construct a nomogram for predicting cancer-specific early death in ovarian cancer patients.

Methods: Our study used data from the Surveillance, Epidemiology, and End Results (SEER) database of ovarian cancer patients registered from 1988 to 2016. Important independent prognostic factors were determined by univariate and multivariate logistic regression and LASSO Cox regression. Several risk factors were considered in constructing the nomogram. Nomogram discrimination and calibration were evaluated using C-index, internal validation, and receiver operating characteristic (ROC) curves.

Results: A total of 4769 patients were included. Patients were assigned to the training set $(n=3340 ; 70 \%)$ and validation set $(n=1429 ; 30 \%)$. Based on the training set, eight variables were shown to be significant factors for early death and were incorporated in the nomogram: AJCC (American Joint Committee on Cancer) stage, residual lesion size, chemotherapy, serum CA125 level, tumor size, number of lymph nodes examined, surgery of primary site, and age. The $\mathrm{C}$-indices and ROC curves showed that the nomogram had better predictive ability than the AJCC staging system and good clinical practicability. Internal validation based on validation set showed good consistency between predicted and observed values for early death.

Conclusions: Compared with predictions made using AJCC stage or residual lesion size, the nomogram was able to provide more robust predictions for early death in ovarian cancer patients.

\section{Synopsis}

Using the large SEER database, we constructed a nomogram incorporating eight factors associated with early death in ovarian cancer patients. The nomogram gave robust predictions of early death and could be an effective method for screening high-risk patients.

\section{Introduction}

Ovarian cancer is the most common malignant tumor in the female reproductive system. Though relatively rare, with an incidence rate of $0.0119 \%{ }^{1}$, it is the seventh most common cancer in women ${ }^{2}$ and has a high recurrence risk. It also has the second highest mortality and the worst prognosis among the major gynecologic cancers ${ }^{3,4}$ (endometrial cancer, cervical cancer, and ovarian cancer). Its 5-year survival rate after diagnosis varies widely among countries, at $46 \%$ in the United States ${ }^{5}$ and ranging from $26-$ $51 \%$ elsewhere ${ }^{6}$. According to US and UK studies, the mortality to morbidity ratio of ovarian cancer is greater than 0.6 , with one in six women dying within 90 days after diagnosis ${ }^{3}$. Epithelial ovarian cancer (EOC), the most common type of ovarian cancer ${ }^{7}$, accounts for more than $95 \%$ of ovarian malignant tumors. Compared with other types, it has higher incidence and mortality rates and has different 
histopathological features, including cell sources, morphology, molecular characteristics, epidemiological factors, clinical characteristics, and survival patterns. Sixty percent of EOC patients develop distant disease, and the average 5 -year survival rate is only $29 \%{ }^{1}$.

Early-stage ovarian cancer has no symptoms, and no methods can effectively monitor them. The primary treatment is surgery and postoperative chemotherapy, which are considerable burdens to the patient. Identifying high-risk factors for ovarian cancer can provide individualized advice and guidance for surgical procedures early in the diagnosis. Ovarian cancer also has a high early death (ED) rate, and exploring factors related to ED can help clinicians identify high-risk patients and develop targeted treatment to improve their survival and quality of life. Therefore, it is necessary to establish an ED prediction model for ovarian cancer to help gynecological oncologists individualize treatments. To our knowledge, no study has been conducted for predicting ED in ovarian cancer postoperatively.

Nomograms are widely used tools that predict incidence and prognosis by combining multiple variables in a single chart. Gynecologists have consistently aimed to improve ovarian cancer survival rates and have recently shown interest in nomograms. However, there are currently no nomograms for the visual prediction, especially postoperatively, of ED in EOC. Although there are studies on the prognosis of malignant tumors, most focus on long-term survival. Few studies focused on ED, and these were based on small samples or regionally limited cohorts ${ }^{6,8,9}$.

The SEER database is an authoritative source of information on cancer incidence and survival status in the United States (https://seer.cancer.gov), representing a sum of statistics from population-based registries that cover over one-third of the US population. Unlike single-center studies, the SEER registry publishes and regularly updates extensive data on patient demographics, primary tumor site, tumor morphology, disease extent, first course of treatment, and active follow-up for vital status. In this study, we used the SEER database to evaluate related factors and construct a nomogram for predicting ED in EOC.

\section{Material And Methods}

\section{Ethics statement}

This study used the SEER database and does not require informed consent. Standard ethical standards were met.

\section{Study population}

We used SEER *Stat version 8.3.9 to extract data on EOC patients between 1988 and 2016. The inclusion criteria were the site code for ovary (C56.9) and histology codes for: Serous (8441-8442, 8460-8463, 9014); Mucinous (8144, 8384, 8470-8472, 8480-8482); Endometrioid (8380-8383); Clear cell (8310, $8313,8443-8444,9110)$; Transitional cell $(8120,8122,8130,9000)$; and Epithelial stromal (8800-8801, $8804-8805,8810,8814,8840,8850-8851,8854,8890-8891,8896,8900-8902,8920-8921,8930-$ 
$8931,8933,8935,8936,8950)$, according to the International Classification of Tumor Diseases, Third Edition (ICD-0-3). The exclusion criteria were (1) unknown cause of death, (2) unknown survival time, (3) unknown tumor size, (4) unknown lymph node information, (5) unknown surgical treatment, (6) unknown race, and (7) unknown staging. Figure 1 shows the patient selection criteria flow chart.

"Early stage" ovarian cancer death is not clearly defined in the literature. Urban et al..$^{8}$ defined it as 3 months based on economic definitions, while Mosgaard et al. ${ }^{6}$ and Lefur et al. ${ }^{9}$ defined it as 6 months. Therefore, in our study, we included postoperative patients with a follow-up time of less than or equal to 6 months and studied ED from ovarian cancer at 1, 3, and 6 months.

\section{Data collection}

Patient demographics and clinical characteristics were extracted from the SEER database, including age, race, marital status, AJCC stage, laterality, surgery of primary site, chemo- and radiotherapy, regional lymph node status (number examined and positive or negative), tumor size, serum CA125 level, residual lesion size, grade, histological type, and metastases to the bone, brain, liver, and lung. We focused on cancer-specific ED.

\section{Statistical analysis and nomogram construction}

X-tile was used to stratify age, number of lymph nodes examined, number of lymph nodes positive, and tumor size ${ }^{10}$. The cutoff values of age were 62 and 72 years old; number of lymph nodes examined, 2; lymph nodes status, positive or negative; and tumor size, $90 \mathrm{~mm}$ (Fig. 2a-d). Patients included in the study were divided into the training set and validation set at a ratio of $7: 3$, respectively. $R$ (version 3.6.0) was used to analyze all data in an R Studio environment. Univariate Cox regression was used to assess the factors associated with ED. Variables that showed statistical significance $(P<0.05)$ were included in the LASSO regression analysis.

Variables that remained significant after LASSO regression analysis were included in the multivariate Cox regression analysis. A $P$ value $<0.01$ was used as the modeling index. The rms package in $\mathrm{R}$ software was used to establish the nomogram for predicting ED based on the associated risk factors in ovarian cancer patients. The pROC package was used to generate ROC curves. The nomogram was internally validated in the validation set based on the area under curve (AUC). The original data and validation model were compared using the concordance index (C-index) to evaluate the calibration accuracy. Nomogram discrimination was measured with the $\mathrm{C}$-index at the $95 \%$ confidence level, which quantifies the degree of agreement between the prediction probability and the actual occurrence probability. A larger C-index indicates a more accurate prediction of prognosis. The primary terminus of the observed event was cancer-specific ED. The classified variables are presented as frequency (\%), hazard ratio, and $95 \%$ confidence interval $(\mathrm{Cl})$.

\section{Results}




\section{Patient characteristics and survival outcomes}

Based on the inclusion and exclusion criteria, 4769 patients were included in the study. Most EDs occurred in patients who were white (83.58\%). Most patients had no metastasis, and all patients underwent surgery. Fifty-nine patients (1.24\%) underwent radiotherapy and 2610 (54.73\%) underwent chemotherapy. The patients were divided into the training set $(n=3340 ; 70 \%)$ and the validation set $(n=$ $1429 ; 30 \%)$. Patient characteristics for both sets are shown in Table 1.

Table 1

Patient characteristics for both sets

\section{Risk factor analysis for early death}

Table 2 shows the results of the univariate COX regression analysis. Twelve characteristics showed a higher risk of cancer-specific ED, including older age, black, married, stage IV, bilateral disease, fertilitysparing surgery, no chemotherapy, no lymph nodes removed, larger tumor size, positive CA125 level, larger residual lesion size, and positive lymph nodes $(P<0.05)$. LASSO Cox regression analysis with the above variables showed that the following were involved in the composition of cancer-specific survival (CSS) risk factors: age, race, marital status, AJCC stage, laterality, surgery of primary site, chemotherapy, number of lymph nodes examined, tumor size, serum CA125 level, and residual lesion size (Fig. 2e). Multivariate Cox regression analysis showed a higher rate of cancer-specific ED for patients who were older, black, married, had no or unknown chemotherapy, large residual lesion size, higher stage disease, positive CA125 level, no or unknown number of lymph nodes examined, fertility-sparing surgery, larger tumor size, and unilateral onset (Table 2). 
Characteristic

All Training Validation $p \quad$ SMD Missing patients, set, set,

\begin{tabular}{|c|c|c|c|c|c|c|}
\hline & $\mathrm{n}(\%)$ & $\mathrm{n}(\%)$ & $\mathrm{n}(\%)$ & & & \\
\hline Total & $\begin{array}{l}4769 \\
(100.0)\end{array}$ & $\begin{array}{l}3340 \\
(70.0)\end{array}$ & $\begin{array}{l}1429 \\
(30.0)\end{array}$ & & & \\
\hline Age, years & & & & 0.555 & 0.034 & 0 \\
\hline $17-62$ & $\begin{array}{l}2021 \\
(42.4)\end{array}$ & $\begin{array}{l}1426 \\
(42.7)\end{array}$ & $\begin{array}{l}595 \\
(41.6)\end{array}$ & & & \\
\hline $63-72$ & $\begin{array}{l}1160 \\
(24.3)\end{array}$ & $\begin{array}{l}818 \\
(24.5)\end{array}$ & $\begin{array}{l}342 \\
(23.9)\end{array}$ & & & \\
\hline $73-96$ & $\begin{array}{l}1588 \\
(33.3)\end{array}$ & $\begin{array}{l}1096 \\
(32.8)\end{array}$ & $\begin{array}{l}492 \\
(34.4)\end{array}$ & & & \\
\hline Race & & & & 0.638 & 0.051 & 0 \\
\hline White & $\begin{array}{l}3986 \\
(83.6)\end{array}$ & $\begin{array}{l}2784 \\
(83.4)\end{array}$ & $\begin{array}{l}1202 \\
(84.1)\end{array}$ & & & \\
\hline Black & $\begin{array}{l}347 \\
(7.3)\end{array}$ & $\begin{array}{l}254 \\
(7.6)\end{array}$ & $93(6.5)$ & & & \\
\hline Asian & $\begin{array}{l}387 \\
(8.1)\end{array}$ & $\begin{array}{l}269 \\
(8.1)\end{array}$ & $118(8.3)$ & & & \\
\hline American Indian & $30(0.6)$ & $19(0.6)$ & $11(0.8)$ & & & \\
\hline Unknown & $19(0.4)$ & $14(0.4)$ & $5(0.3)$ & & & \\
\hline Marital status & & & & 0.757 & 0.043 & 0 \\
\hline Single & $\begin{array}{l}839 \\
(17.6)\end{array}$ & $\begin{array}{l}596 \\
(17.8)\end{array}$ & $\begin{array}{l}243 \\
(17.0)\end{array}$ & & & \\
\hline Married & $\begin{array}{l}2204 \\
(46.2)\end{array}$ & $\begin{array}{l}1544 \\
(46.2)\end{array}$ & $\begin{array}{l}660 \\
(46.2)\end{array}$ & & & \\
\hline Widowed/Separated & $\begin{array}{l}1099 \\
(23.1)\end{array}$ & $\begin{array}{l}755 \\
(22.6)\end{array}$ & $\begin{array}{l}344 \\
(24.1)\end{array}$ & & & \\
\hline Divorced & $\begin{array}{l}464 \\
(9.7)\end{array}$ & $\begin{array}{l}332 \\
(9.9)\end{array}$ & $132(9.2)$ & & & \\
\hline Unknown & $\begin{array}{l}163 \\
(3.4)\end{array}$ & $\begin{array}{l}113 \\
(3.4)\end{array}$ & $50(3.5)$ & & & \\
\hline AJCC stage & & & & 0.842 & 0.029 & 0 \\
\hline I & $\begin{array}{l}676 \\
(14.2)\end{array}$ & $\begin{array}{l}482 \\
(14.4)\end{array}$ & $\begin{array}{l}194 \\
(13.6)\end{array}$ & & & \\
\hline II & $\begin{array}{l}313 \\
(6.6)\end{array}$ & $\begin{array}{l}215 \\
(6.4)\end{array}$ & $98(6.9)$ & & & \\
\hline
\end{tabular}




$\begin{array}{llll}\text { III } & 2134 & 1490 & 644 \\ & (44.7) & (44.6) & (45.1) \\ \text { IV } & 1646 & 1153 & 493 \\ & (34.5) & (34.5) & (34.5)\end{array}$

\section{Laterality}

Unilateral

2479

(52.0)

1756

(52.6)

723

197

Paired

(4.1)

129

(3.9)

Bilateral

2093
$(43.9)$

1455

(43.6)

638

(44.6)

\section{$0.227 \quad 0.054 \quad 0$}

$68(4.8)$

\section{Surgery of primary site}

Fertility-sparing

Fertility-sparing

Non-fertility sparing

438

(9.2)

Debulking

\begin{tabular}{lll}
1334 & 949 & 385 \\
$(28.0)$ & $(28.4)$ & $(26.9)$ \\
2092 & 1450 & 642 \\
$(43.8)$ & $(43.4)$ & $(44.9)$ \\
\hline
\end{tabular}

\section{Chemotherapy}

None/Unknown

905

(19.0)

624

(18.7)

Pelvic exenteration

Yes

438

317

(9.5)

$0.499 \quad 0.058 \quad 0$

\begin{tabular}{l} 
Debulking \\
\hline Pelvic exenteration \\
\hline Chemotherapy \\
\hline None/Unknown \\
\hline Yes \\
\hline Number of lymph nodes examined \\
\hline
\end{tabular}

No regional nodes removed/

number of nodes is unknown

0-2

$\geq 3$

\section{Tumor size}

Unknown

$\leq 90 \mathrm{~mm}$

$>90 \mathrm{~mm}$

$\begin{array}{lll}2159 & 1500 & 659 \\ (45.3) & (44.9) & (46.1) \\ 2610 & 1840 & 770 \\ (54.7) & (55.1) & (53.9)\end{array}$

$\begin{array}{lll}0.463 & 0.024 & 0\end{array}$
281

(19.7)

$121(8.5)$

(44.9) 
$(13.7) \quad(14.0) \quad$ (12.9)

Serum CA125 level

$\begin{array}{lll}0.662 & 0.029 & 0\end{array}$

Negative

206

(4.3)

150

(4.5)

Borderline

Positive

Residual lesion size

No residual lesion

$\leq 1 \mathrm{~cm}$

$>1 \mathrm{~cm}$

Residual unknown

Lymph node status

No nodes examined/ unknown status

Unknown number of positive nodes

Negative

Positive

\section{Grade}$$
\text { । }
$$

॥

III

IV

$\begin{array}{lll}2337 & 1631 & 706 \\ (49.0) & (48.8) & (49.4) \\ 2226 & 1559 & 667 \\ (46.7) & (46.7) & (46.7)\end{array}$

$\begin{array}{lll}0.926 & 0.022 & 0\end{array}$

$1027 \quad 725 \quad 302$

(21.5) (21.7) (21.1)

$224 \quad 160 \quad 64(4.5)$

(4.7) (4.8)

$160 \quad 112$

(3.4)

(3.4)

$\begin{array}{lll}3358 & 2343 & 1015 \\ (70.4) & (70.1) & (71.0)\end{array}$

48 (3.4)

(71.0) 


\begin{tabular}{|c|c|c|c|c|c|c|}
\hline Mucinous & $\begin{array}{l}595 \\
(12.5)\end{array}$ & $\begin{array}{l}431 \\
(12.9)\end{array}$ & $\begin{array}{l}164 \\
(11.5)\end{array}$ & & & \\
\hline Endometrioid & $\begin{array}{l}565 \\
(11.8)\end{array}$ & $\begin{array}{l}406 \\
(12.2)\end{array}$ & $\begin{array}{l}159 \\
(11.1)\end{array}$ & & & \\
\hline Clear cell & $\begin{array}{l}314 \\
(6.6)\end{array}$ & $\begin{array}{l}217 \\
(6.5)\end{array}$ & $97(6.8)$ & & & \\
\hline Transitional & $22(0.5)$ & $15(0.4)$ & $7(0.5)$ & & & \\
\hline Epithelial-stromal & $\begin{array}{l}317 \\
(6.6)\end{array}$ & $\begin{array}{l}230 \\
(6.9)\end{array}$ & $87(6.1)$ & & & \\
\hline Radiotherapy & & & & 0.736 & 0.015 & 0 \\
\hline None/Unknown & $\begin{array}{l}4710 \\
(98.8)\end{array}$ & $\begin{array}{l}3297 \\
(98.7)\end{array}$ & $\begin{array}{l}1413 \\
(98.9)\end{array}$ & & & \\
\hline Yes & $59(1.2)$ & $43(1.3)$ & $16(1.1)$ & & & \\
\hline Bone metastasis & & & & 0.956 & 0.01 & 0 \\
\hline None/Unknown & $\begin{array}{l}4751 \\
(99.6)\end{array}$ & $\begin{array}{l}3328 \\
(99.6)\end{array}$ & $\begin{array}{l}1423 \\
(99.6)\end{array}$ & & & \\
\hline Yes & $18(0.4)$ & $12(0.4)$ & $6(0.4)$ & & & \\
\hline Brain metastasis & & & & 0.449 & 0.038 & 0 \\
\hline None/Unknown & $\begin{array}{l}4766 \\
(100.0)\end{array}$ & $\begin{array}{l}3339 \\
(100.0)\end{array}$ & $\begin{array}{l}1427 \\
(99.9)\end{array}$ & & & \\
\hline Yes & $3(0.00)$ & $1(0.0)$ & $2(0.1)$ & & & \\
\hline Liver metastasis & & & & 0.421 & 0.029 & 0 \\
\hline None/Unknown & $\begin{array}{l}4619 \\
(96.9)\end{array}$ & $\begin{array}{l}3230 \\
(96.7)\end{array}$ & $\begin{array}{l}1389 \\
(97.2)\end{array}$ & & & \\
\hline Yes & $\begin{array}{l}150 \\
(3.1)\end{array}$ & $\begin{array}{l}110 \\
(3.3)\end{array}$ & $40(2.8)$ & & & \\
\hline Lung metastasis & & & & 0.705 & 0.016 & 0 \\
\hline None/Unknown & $\begin{array}{l}4675 \\
(98.0)\end{array}$ & $\begin{array}{l}3272 \\
(98.0)\end{array}$ & $\begin{array}{l}1403 \\
(98.2)\end{array}$ & & & \\
\hline Yes & $94(2.0)$ & $68(2.0)$ & $26(1.8)$ & & & \\
\hline
\end{tabular}

SMD, standardized mean difference 
TABLE 2

Univariate and multivariate Cox regression analysis of cancer-specific mortality

\begin{tabular}{|c|c|c|c|c|c|c|}
\hline \multirow[b]{2}{*}{ Characteristic } & \multicolumn{3}{|c|}{ Univariate Cox Regression } & \multicolumn{3}{|c|}{ Multivariate Cox Regression } \\
\hline & $\mathrm{HR}$ & $95 \% \mathrm{Cl}$ & $\mathrm{p}$-value & $H R$ & $\begin{array}{l}95 \% \\
\mathrm{Cl}\end{array}$ & $p$-value \\
\hline Age, years & 1.599 & $\begin{array}{l}1.522- \\
1.679\end{array}$ & $<0.001$ & & & \\
\hline $17-62$ & & & & Reference & & \\
\hline $63-72$ & & & & 1.175 & $\begin{array}{l}1.047- \\
1.318\end{array}$ & 0.006096 \\
\hline $73-96$ & & & & 1.342 & $\begin{array}{l}1.194- \\
1.509\end{array}$ & $<0.001$ \\
\hline Race & 0.859 & $\begin{array}{l}0.803- \\
0.919\end{array}$ & 0.002 & & & \\
\hline White & & & & Reference & & \\
\hline Black & & & & 1.080 & $\begin{array}{l}0.922- \\
1.264\end{array}$ & 0.340927 \\
\hline Asian & & & & 0.959 & $\begin{array}{l}0.804- \\
1.144\end{array}$ & 0.640988 \\
\hline American Indian & & & & 0.799 & $\begin{array}{l}0.470- \\
1.360\end{array}$ & 0.409096 \\
\hline Unknown & & & & 0.288 & $\begin{array}{l}0.072- \\
1.155\end{array}$ & 0.05 \\
\hline Marital status & 1.115 & $\begin{array}{l}1.072- \\
1.161\end{array}$ & $<0.001$ & & & \\
\hline Single & & & & Reference & & \\
\hline Married & & & & 1.014 & $\begin{array}{l}0.891- \\
1.154\end{array}$ & 0.827977 \\
\hline Widowed/Separated & & & & 0.993 & $\begin{array}{l}0.857- \\
1.151\end{array}$ & 0.925082 \\
\hline Divorced & & & & 0.916 & $\begin{array}{l}0.769- \\
1.090\end{array}$ & 0.321994 \\
\hline Unknown & & & & 0.760 & $\begin{array}{l}0.581- \\
0.996\end{array}$ & 0.046391 \\
\hline AJCC stage & 1.568 & $\begin{array}{l}1.492- \\
1.648\end{array}$ & $<0.001$ & & & \\
\hline I & & & & Reference & & \\
\hline
\end{tabular}




\begin{tabular}{|c|c|c|c|c|c|c|}
\hline II & & & & 2.233 & $\begin{array}{l}1.677- \\
2.972\end{array}$ & $<0.001$ \\
\hline III & & & & 3.220 & $\begin{array}{l}2.571- \\
4.033\end{array}$ & $<0.001$ \\
\hline IV & & & & 3.596 & $\begin{array}{l}2.862- \\
4.519\end{array}$ & $<0.001$ \\
\hline Laterality & 1.101 & $\begin{array}{l}1.055- \\
1.148\end{array}$ & $<0.001$ & & & \\
\hline Unilateral & & & & Reference & & \\
\hline Paired & & & & 0.932 & $\begin{array}{l}0.757- \\
1.147\end{array}$ & 0.504569 \\
\hline Bilateral & & & & 1.054 & $\begin{array}{l}0.964- \\
1.153\end{array}$ & 0.248700 \\
\hline
\end{tabular}

Fertility-sparing

Non-fertility sparing

Debulking

Pelvic exenteration

\section{Chemotherapy}

None/Unknown

Yes

Number of lymph nodes examined

No regional nodes removed/ number of nodes is unknown

0-2

$\geq 3$

\section{Tumor size}

Unknown
0.828
$0.799-$
$<0.001$

Reference

$\begin{array}{lll}0.840 & 0.709- & 0.043971 \\ & 0.995 & \end{array}$

0.651

$\begin{array}{ll}0.569- & <0.001 \\ 0.744 & \end{array}$

0.750

$0.667-\quad<0.001$ 0.844
$0.352 \quad 0.324-\quad<0.001$

0.383
Reference

$\begin{array}{lll}0.391 & 0.357- & <0.001 \\ & 0.430\end{array}$

$0.537 \quad 0.495-\quad<0.001$ 0.582
Reference
0.783
$0.639-\quad 0.017434$
0.958
0.637
$0.512-<0.001$
0.792
1.185
$1.124-$
1.249
$<0.001$

Reference 


\begin{tabular}{|c|c|c|c|c|c|c|}
\hline$\leq 90 \mathrm{~mm}$ & & & & 1.700 & $\begin{array}{l}1.499- \\
1.927\end{array}$ & $<0.001$ \\
\hline$>90 \mathrm{~mm}$ & & & & 1.773 & $\begin{array}{l}1.561- \\
2.013\end{array}$ & $<0.001$ \\
\hline Serum CA125 level & 1.991 & $\begin{array}{l}1.841- \\
2.154\end{array}$ & $<0.001$ & & & \\
\hline Negative & & & & Reference & & \\
\hline Borderline & & & & 1.290 & $\begin{array}{l}0.932- \\
1.787\end{array}$ & 0.125217 \\
\hline Positive & & & & 1.858 & $\begin{array}{l}1.339- \\
2.580\end{array}$ & $<0.001$ \\
\hline Residual lesion size & 1.715 & $\begin{array}{l}1.632- \\
1.801\end{array}$ & $<0.001$ & & & \\
\hline No residual lesion & & & & Reference & & \\
\hline$\leq 1 \mathrm{~cm}$ & & & & 1.355 & $\begin{array}{l}1.019- \\
1.800\end{array}$ & 0.036478 \\
\hline$>1 \mathrm{~cm}$ & & & & 1.901 & $\begin{array}{l}1.388- \\
2.605\end{array}$ & $<0.001$ \\
\hline Residual unknown & & & & 2.718 & $\begin{array}{l}2.296- \\
3.218\end{array}$ & $<0.001$ \\
\hline Lymph node status & 0.817 & $\begin{array}{l}0.788- \\
0.846\end{array}$ & $<0.001$ & & & \\
\hline Grade & 1.001 & $\begin{array}{l}0.956- \\
1.049\end{array}$ & 0.959 & & & \\
\hline Histological type & 1.003 & $\begin{array}{l}0.975- \\
1.032\end{array}$ & 0.845 & & & \\
\hline Radiotherapy & 0.969 & $\begin{array}{l}0.684- \\
1.374\end{array}$ & 0.860 & & & \\
\hline Bone metastasis & 0.825 & $\begin{array}{l}0.412- \\
1.652\end{array}$ & 0.587 & & & \\
\hline Brain metastasis & 2.456 & $\begin{array}{l}0.346- \\
17.453\end{array}$ & 0.369 & & & \\
\hline Liver metastasis & 0.856 & $\begin{array}{l}0.665- \\
1.102\end{array}$ & 0.229 & & & \\
\hline Lung metastasis & 0.808 & $\begin{array}{l}0.589- \\
1.109\end{array}$ & 0.188 & & & \\
\hline
\end{tabular}

$\mathrm{HR}$, hazard ratio; $\mathrm{Cl}$, confidence interval 


\section{Nomogram construction}

Multivariate regression analysis revealed that AJCC stage, residual lesion size, chemotherapy, serum CA125 level, tumor size, number of lymph nodes examined, surgery of primary site, and age were significantly associated to ED $(P<0.05)$. These eight variables were used to construct a nomogram for predicting cancer-specific ED (Fig. 3). The procedure for using the nomogram is as follows: based on the patient's status, a vertical line is drawn from each prediction variable to the "Score" axis. Each prediction variable is then assigned the corresponding points shown by the intersection of the vertical line with the "Score" axis. The points from all variables are added to obtain the total points, which is used to draw another vertical line from the "Total Points" axis to the probability axes. The intersection of this line with the 1-, 3-, and 6-month axes shows the probability of cancer-specific ED for those time intervals. The Cindices of the training and validation set were 0.787 (95\% Cl: $0.772-0.794), 0.763$ (95\% Cl: $0.745-0.780)$, respectively, indicating good consistency between the predicted and observed values.

\section{Performance of nomogram}

Figure 4a shows the ROC curves of the training set. The AUCs of the nomogram for 1-, 3-, and 6-month ED were $0.801,0.812$, and 0.880 , respectively. All three values are above 0.5 and close to 1 , suggesting that the nomogram gives reliable predictions of cancer-specific ED. When predicting survival time using the AJCC stage, the AUCs for 1,3 , and 6 months were $0.591,0.631$, and 0.715 , respectively. Similarly, predict the prognosis using residual lesion size showed AUCs of $0.627,0.655$, and 0.770 , respectively. For all three time intervals, AUCs were largest when using the nomogram, indicating that the nomogram gives the most accurate prediction. We also compared the time-dependence of the nomogram and AJCC stage prediction (Fig. 4b) and found that the nomogram performed better. Internal validation of the nomogram using a scatter plot of the actual probability (Y-axis) against the predicted probability ( $\mathrm{X}$-axis) showed that the calibration curves for all three time intervals are close to the $45^{\circ}$ line, which indicates good calibration (Fig. 5a). In addition, Kaplan-Meier curves (Fig. 6a) were drawn to determine the difference in survival between high- and low-risk patients. Log-rank test was used to differentiate the survival rate, and statistical significance was set at $P<0.0001$. We also conducted a decision curve analysis (DCA) (Fig. 7a).

\section{Nomogram validation}

The nomogram was validated in the validation set. Figure 4c shows the ROC curves of the nomogram, AJCC stage, and residual lesion size predictions of cancer-specific ED. When using nomogram, the AUCs for 1,3 , and 6 months were: $0.798,0.781$, and 0.897 , respectively; when using the AJCC stage: 0.602 , 0.628 , and 0.741 ; and when using residual lesion size: $0.635,0.639$, and 0.786 . In the validation set, the AUC of the nomogram is still higher compared with those of the AJCC stage or residual lesion size predictions, indicating the superiority of the nomogram. This is also confirmed in the curves showing the time-dependence of AUC (Fig. 4d) and the DCA curve (Fig. 7b). As shown in Fig. 5b, the calibration curves for all three-time intervals are also close to the $45^{\circ}$ line. Based on the median risk score derived from the nomogram, the Kaplan-Meier curve also showed significant differences between the low-risk and high-risk 
groups (Fig. 6b; validation set, $\mathrm{P}<0.001$ ). This indicates that the nomogram can effectively stratify risk. Internal validation of the nomogram in the validation set indicated good consistency between the predicted and observed values.

\section{Discussion}

In this study, the ED rates of EOC at 1, 3, and 6 months post-operation were $9.98 \%, 18.73 \%$, and $33.34 \%$, respectively. Identifying patients at risk of ED is essential to reduce the burden on patients. Our results show that ED from ovarian cancer is mainly related the clinical factors AJCC stage, residual lesion size, chemotherapy, serum CA125 level, tumor size, number of lymph nodes examined, surgery of primary site, and age. Therefore, we constructed a nomogram that integrates these factors for predicting ED in ovarian cancer patients.

Comparing the ROCs and time-dependent AUCs shows that the nomogram had higher predictive power than the AJCC staging system. AJCC staging is commonly used to clinically evaluate ovarian cancer prognosis but is limited in that it cannot give individualized predictions. Additional clinical factors, such as those included in our nomogram, are often ignored. Internal validation showed that the ED rate predicted with the nomogram is consistent with the actual ED rate. The C-index of the nomogram was 0.787 , which represents a better degree of differentiation and ability to provide individualized prediction compared with the AJCC stage. In addition, both the training and validation sets showed good consistency with observed values.

Nomograms have been widely used to evaluate the prognosis and death risk in malignant tumor patients. Chen et al. ${ }^{11}$ studied all-cause and specific mortalities of ovarian clear cell carcinoma and constructed a nomogram with the prognostic factors age, laterality, organ metastasis, AJCC stage, number of lymphadenectomies, and chemotherapy. Yuan et al. ${ }^{12}$ assessed lung metastasis incidence in ovarian cancer and proposed that stage, liver, bone, and brain metastases and TN stage are predictors of lung metastasis. The nomogram constructed by Mosgaard et al. ${ }^{6}$ showed that the survival rate was higher for patients with chemotherapy, smaller residual cancer and tumor size, younger age, lower CA125 level, higher differentiation, debulking surgery, and more lymph node resections. In the present study, analysis and internal validation using ROC and DCA curves showed that the nomogram has good discrimination and calibration. Thus, the nomogram may be an effective tool to predict ED in ovarian cancer patients, guide their individualized treatment, and improve their hospice care and quality of life.

Cancer stage is closely related to cancer survival and ED rates. In our nomogram, stage occupied the entire 100-point scale, with stage I being scored 0 and stage IV being scored 100 . This implies that stage is an important independent influencing factor. This is consistent with the results of previous studies on prognostic evaluation models for pancreatic cancer and uterine sarcoma ${ }^{13,14}$. The prognosis of stage III and IV patients is generally poor and mainly depends on the size of intraperitoneal metastases ${ }^{15}$. As stage progresses, the risk of death increases ${ }^{16,17}$. A large retrospective cohort study based on the SEER 
database suggested that mortality in patients with stage III-IV ovarian cancer is as high as $10 \%$ in 1 $\operatorname{year}^{18}$

After stage, the residual size of cancer foci was the second most influential factor in this study. The larger the residual cancer foci, the higher the chances of ED, which is consistent with the findings of previous studies. Surgery is essential for ovarian cancer treatment, and postoperative residual tumor is one of the most relevant clinical prognostic factors ${ }^{19-21}$. Surgery aimed at minimizing tumor cells can lead to better outcomes. Complete tumor resection is considered a major predictor of survival ${ }^{22}$. Approximately $20 \%$ of patients with advanced ovarian cancer survived for more than 12 years after treatment and were eventually effectively cured. Debulking surgery is performed to eliminate cancer cells and cancer foci as much as possible, preferably without significant residue. An article previously suggested that recovery depends on whether the combination of surgery and chemotherapy can effectively eliminate all cancer cells ${ }^{23}$.

As an important adjuvant treatment for ovarian cancer, chemotherapy is commonly used to kill residual cancer foci and control or treat recurrent foci. In our study, chemotherapy was significantly correlated with prognosis, which was of great value in improving survival outcomes. Chemotherapy can reduce tumors and create conditions for surgery. Major tumor debulking surgery and platinum chemotherapy remain as the standard treatments for patients with stage III-IV EOC. Some patients with International Federation of Obstetrics and Gynecology stage III-IV ovarian cancer may benefit from neoadjuvant chemotherapy ${ }^{24}$. EOC patients (especially high-grade serous cancer) respond well to initial chemotherapy ${ }^{3}$, with approximately $80 \%$ responding to neoadjuvant chemotherapy as an alternative treatment. Poly ADPribose polymerase inhibitors are one of the most studied, most effective, and least toxic drugs, and have therefore become one of the best targeted therapeutic options for treating recurrent EOC, especially in cases of platinum-sensitive recurrent ovarian cancer 25,26 .

Age and stage are independent risk factors for ovarian cancer prognosis ${ }^{6}$. In our study, age, lymph node examined, and tumor size were stratified, with cutoff values of 62 and 72 years for age, 2 for number of lymph nodes examined, and $90 \mathrm{~mm}$ for tumor size. In general, older patients are at higher risk for ovarian cancer and are more likely to have poor survival outcomes due to lower immune responses ${ }^{27}$. However, we observed that age was not highly significant, which may be related to the relatively conservative surgeries and pre- and postoperative chemotherapies given to young patients. In clinical practice, we often explore the pelvic and abdominal cavities of ovarian cancer patients to histologically examine suspected lesions and sites prone to metastasis and to clear the pelvic and abdominal para-aortic lymph nodes. Operation scope is determined according to the results of intraoperative exploration and frozen pathology examinations. The thoroughness of the first operation of EOC is closely related to the prognosis. Lymph node metastasis has an important effect on EOC prognosis. Some scholars suggest that lymph node dissection in advanced EOC may be used as a treatment. The number of lymph nodes examined and the resection of paraaortic lymph nodes may also be helpful ${ }^{28}$. In stage III, the subcategories IIIA and IIIB are based on the presence or absence of gross external pelvic peritoneal

Page $15 / 26$ 
metastasis. However, this method is unable to distinguish the prognosis of patients with different numbers of lymphadenectomy in the same pathological stage. Therefore, we used X-tile to analyze the optimal cutoff value for the number of lymph nodes, which was subsequently included in the prediction after univariate and multivariate analysis.

Serum CA125 level is a high-sensitivity index for disease monitoring. Among EOC patients, Serum CA125 level are higher than the normal value, with more than $90 \%$ being consistent with the remission or deterioration of the disease. Increasing Serum CA125 level is considered an important predictor of death $^{29}$ and is therefore important for predicting prognosis.

The primary ovarian focus in stage I patients are larger than those in stage III patients ${ }^{15}$. In addition, the ovarian foci in early ovarian cancer are more than twice as large as those in advanced ovarian cancer ${ }^{30}$. These support the fact that early and advanced ovarian cancer are two separate disease processes. Early tumors grow locally and do not spread, while advanced tumors that are relatively small are prone to spreading. It has been suggested that there may be a key substance differentiating the two processes; that is, the tumor in patients with advanced disease produces a substance that allows early-stage transmission. Without this substance, the tumor only grows locally.

The standard process for determining treatment in early EOC is clinical/surgical staging, which includes hysterectomy, bilateral ovariectomy, omentum resection, abdominal irrigation, and pelvic and paraaortic lymph node biopsy. Preserving the reproductive function means preserving the uterus and at least one side of the ovary. A study based on the SEER database found that fertility-sparing surgery was associated with an increased risk of death in women with advanced serous EOC ${ }^{31}$. However, some studies have found that the effect of fertility-sparing surgery on survival in stage I ovarian cancer is no worse than that of radical surgery. This suggests that specific histological subtypes have a greater effect on tumor prognosis than the retention of reproductive function. Radical surgery is unlikely to reduce the risk of recurrence of certain histological subtypes ${ }^{32}$. In a previous study, there was no significant difference in overall survival between stage I and radical surgery in $\mathrm{EOC}^{33}$. Prognosis may be more related to the natural history of the disease and the cancer type rather than to the specific type of surgery ${ }^{34}$. The nomogram we constructed refined the prognostic prediction by classifying the surgical modalities. And based on that, it is obviously that the score the difference of surgical type is non-significant.

This study has several limitations. First, our model did not include molecular markers that elucidate ovarian cancer mechanisms as these were not part of the SEER database. Many of these markers have been used to build predictive models for ovarian cancer ${ }^{35}$, including five genes related to glucose metabolism $^{36}$ and 11 genes related to lipid metabolism ${ }^{37}$. MRPS12 may be a promising candidate for prognosis ${ }^{38}$. Second, several factors were also unavailable from the SEER database, including patients' family history, underlying pre-operative diseases, BMI, types of anesthetics, induction time, blood pressure, blood oxygen, heart rate fluctuations, cancer cell detection in pre- and postoperative ascites, thrombosis and surgical incision infection, specific preoperative and postoperative chemotherapy, 
chemotherapy times, and chemotherapeutic agents. Third, we did not analyze humanistic and sociological factors such as income and insurance, which have an important influence on the psychological and physiological aspects of ovarian cancer ${ }^{8}$. We also excluded economic status, education level, and follow-up by gynecologic oncologists, which are considered closely related to ovarian cancer prognosis. Lastly, our study is retrospective and has potential for selection bias since the data were extracted from the SEER database. Without external data validation, a more comprehensive prediction is impossible. Further studies combining our research data with those of others are needed for better prediction.

In conclusion, using a large cohort study, we identified several factors associated with ED in ovarian cancer and constructed a nomogram with better prognostic performance than the AJCC staging system. Our nomogram can be used in future clinical work as a more effective tool for screening high-risk patients. It may also play an important role in predicting ED from ovarian cancer and providing relatively reliable and individualized postoperative treatment advice to improve the quality of life of ovarian cancer patients.

\section{Declarations}

\section{Acknowledgments}

None.

\section{Conflicts of Interest}

The authors declare that there is no conflict of interest regarding the publication of this paper.

\section{Ethical approval statement and informed constent}

This study used the SEER database and does not require informed consent. Standard ethical standards were met.

\section{Funding Statement}

The present study was supported by 345 Talent Project of Shengjing Hospital.

\section{Author contributions}

Tingting Zhang involved in data collection, did the validation and wrote the manuscript. Liancheng Zhu involved in methodology and data statistical analysis, provided fund support and critically reviewed the 
manuscript. All authors read and approved the final manuscript.

\section{References}

1. Doherty JA, Peres LC, Wang C, Way GP, Greene CS, Schildkraut JM (2017) Challenges and Opportunities in Studying the Epidemiology of Ovarian Cancer Subtypes. Curr Epidemiol Rep 4:211220. https://doi.org/10.1007/s40471-017-0115-y

2. Webb PM, Jordan SJ. Epidemiology of epithelial ovarian cancer. Best Pract Res Clin Obstet Gynaecol. (2017) 41:3-14. https://doi.org/10.1016/j.bpobgyn.2016.08.006

3. Lheureux S, Braunstein M, Oza AM (2019) Epithelial ovarian cancer: Evolution of management in the era of precision medicine. CA Cancer J Clin 69:280-304. https://doi.org/10.3322/caac.21559

4. Bowes DE, Tamlyn D, Butler LJ (2002) Women living with ovarian cancer: dealing with an early death. Health Care Women Int 23:135-148. https://doi.org/10.1080/073993302753429013

5. Siegel RL, Miller KD, Jemal A. Cancer statistics (2016) CA Cancer J Clin. (2016) 66:7-30. https://doi.org/10.3322/caac.21332

6. Mosgaard BJ, Meaidi A, Høgdall C, Noer MC (2020) Risk factors for early death among ovarian cancer patients: a nationwide cohort study. J Gynecol Oncol 31:e30. https://doi.org/10.3802/jgo.2020.31.e30

7. Torre LA, Trabert B, DeSantis CE et al (2018) Ovarian cancer statistics, 2018. CA Cancer J Clin 68:284-296. https://doi.org/10.3322/caac.21456

8. Urban RR, He H, Alfonso R, Hardesty MM, Gray HJ, Goff BA (2016) Ovarian cancer outcomes: Predictors of early death. Gynecol Oncol 140:474-480. https://doi.org/10.1016/j.ygyno.2015.12.021

9. Lefur E, Berton-Rigaud D, Boureau AS, Chapelet G, Berrut G, de Decker L (2014) Early death in advanced ovarian cancer in older adults. J Am Geriatr Soc 62:976-977. https://doi.org/10.1111/jgs.12808

10. Camp RL, Dolled-Filhart M, Rimm DL (2004) X-tile: a new bio-informatics tool for biomarker assessment and outcome-based cut-point optimization. Clin Cancer Res 10:7252-7259. https://doi.org/10.1158/1078-0432.CCR-04-0713

11. Chen Q, Wang S, Lang JH (2020) Development and validation of Nomograms for predicting overall survival and Cancer-specific survival in patients with ovarian clear cell carcinoma. J Ovarian Res 13:123. https://doi.org/10.1186/s13048-020-00727-3

12. Yuan Y, Guo F, Wang R, Zhang Y, Bai G (2020) Development and validation of a nomogram to predict synchronous lung metastases in patients with ovarian cancer: a large cohort study. Biosci Rep 40:BSR20203089. https://doi.org/10.1042/BSR20203089

13. Shi M, Zhou B, Yang SP. Nomograms for predicting overall survival and cancer-specific survival in young patients with pancreatic cancer in the US based on the SEER database. PeerJ. (2020) 8:e8958. https://doi.org/10.7717/peerj.8958 
14. Song Z, Wang Y, Zhang D, Zhou Y (2020) A Novel Tool to Predict Early Death in Uterine Sarcoma Patients: A Surveillance, Epidemiology, and End Results-Based Study. Front Oncol 10:608548. https://doi.org/10.3389/fonc.2020.608548

15. Petru E, Huber C, Sampl E, Haas J. Comparison of Primary Tumor Size in Stage I and III Epithelial Ovarian Cancer. Anticancer Res. (2018) 38:6507-6511. https://doi.org/10.21873/anticanres.13015

16. Huang Y, Ming X, Li B, Li Z (2020) Histological Characteristics and Early-Stage Diagnosis Are Associated With Better Survival in Young Patients With Epithelial Ovarian Cancer: A Retrospective Analysis Based on Surveillance Epidemiology and End Results Database. Front Oncol 10:595789. https://doi.org/10.3389/fonc.2020.595789

17. Maringe $\mathrm{C}$, Walters $\mathrm{S}$, Butler $\mathrm{J}$ et al. Stage at diagnosis and ovarian cancer survival: evidence from the International Cancer Benchmarking Partnership. Gynecol Oncol. (2012) 127:75-82. https://doi.org/10.1016/j.ygyno.2012.06.033

18. Wu S, Feng Y, Jian L et al. Histological Tumor Type is Associated with One-Year Cause-Specific Survival in Women with Stage III-IV Epithelial Ovarian Cancer: A Surveillance, Epidemiology, and End Results (SEER) Database Population Study, 2004-2014. Med Sci Monit. (2020) 26:e920531. https://doi.org/10.12659/MSM.920531

19. Sehouli J, Grabowski JP. Surgery in recurrent ovarian cancer. Cancer. (2019) 125 Suppl 24:45984601. https://doi.org/10.1002/cncr.32511

20. Melamed A, Manning-Geist B, Bregar AJ et al (2017) Associations between residual disease and survival in epithelial ovarian cancer by histologic type. Gynecol Oncol 147:250-256. https://doi.org/10.1016/j.ygyno.2017.08.003

21. Winter WE, Maxwell GL, Tian C et al (2008) Tumor residual after surgical cytoreduction in prediction of clinical outcome in stage IV epithelial ovarian cancer: a Gynecologic Oncology Group Study. J Clin Oncol 26:83-89. https://doi.org/10.1200/JC0.2007.13.1953

22. Heintz AP, Odicino F, Maisonneuve P et al Carcinoma of the ovary. FIGO 26th Annual Report on the Results of Treatment in Gynecological Cancer. Int J Gynecol Obstet (2006) 95:S161-S192. https://doi.org/10.1016/S0020-7292(06)60033-7

23. Narod S (2016) Can advanced-stage ovarian cancer be cured? Nat Rev Clin Oncol 13:255-261. https://doi.org/10.1038/nrclinonc.2015.224

24. Nishio S, Ushijima K (2020) Clinical significance of primary debulking surgery and neoadjuvant chemotherapy-interval debulking surgery in advanced ovarian cancer. Jpn J Clin Oncol 50:379-386. https://doi.org/10.1093/jjco/hyaa015

25. Evans T, Matulonis U (2017) PARP inhibitors in ovarian cancer: evidence, experience and clinical potential. Ther Adv Med Oncol 9:253-267. https://doi.org/10.1177/1758834016687254

26. Gupta S, Nag S, Aggarwal S, Rauthan A, Warrier N (2019) Maintenance therapy for recurrent epithelial ovarian cancer: current therapies and future perspectives - a review. J Ovarian Res 12:103. https://doi.org/10.1186/s13048-019-0579-0 
27. Pawelec G. Does patient age influence anti-cancer immunity? Semin Immunopathol. (2019) 41:125131. https://doi.org/10.1007/s00281-018-0697-6

28. Ercelep O, Ozcelik M, Gumus M (2019) Association of lymphadenectomy and survival in epithelial ovarian cancer. Curr Probl Cancer 43:151-159. https://doi.org/10.1016/j.currproblcancer.2018.08.002

29. Cao Y, Jiang Y, Lin X et al (2018) Dynamic Prediction of Outcome for Patients With Ovarian Cancer: Application of a Joint Model for Longitudinal Cancer Antigen 125 Values. Int J Gynecol Cancer 28:85-91. https://doi.org/10.1097/IGC.0000000000001134

30. Horvath LE, Werner T, Boucher K, Jones K (2013) The relationship between tumor size and stage in early versus advanced ovarian cancer. Med Hypotheses 80:684-687. https://doi.org/10.1016/j.mehy.2013.01.027

31. Crafton SM, Cohn DE, Llamocca EN, Louden E, Rhoades J, Felix AS (2020) Fertility-sparing surgery and survival among reproductive-age women with epithelial ovarian cancer in 2 cancer registries. Cancer 126:1217-1224. https://doi.org/10.1002/cncr.32620

32. Johansen G, Dahm-Kähler P, Staf C, Flöter Rådestad A, Rodriguez-Wallberg KA. A Swedish Nationwide prospective study of oncological and reproductive outcome following fertility-sparing surgery for treatment of early stage epithelial ovarian cancer in young women. BMC Cancer. (2020) 20:1009. https://doi.org/10.1186/s12885-020-07511-y

33. Liu D, Cai J, Gao A, Wang Z, Cai L (2020) Fertility sparing surgery vs radical surgery for epithelial ovarian cancer: a meta-analysis of overall survival and disease-free survival. BMC Cancer 20:320. https://doi.org/10.1186/s12885-020-06828-y

34. Bentivegna E, Morice P, Uzan C, Gouy S (2016) Fertility-sparing surgery in epithelial ovarian cancer. Future Oncol 12:389-398. https://doi.org/10.2217/fon.15.319

35. Kobayashi Y, Banno K, Aoki D (2021) Current status and future directions of ovarian cancer prognostic models. J Gynecol Oncol 32:e34. https://doi.org/10.3802/jgo.2021.32.e34

36. Liu L, Cai L, Liu C et al (2020) Construction and Validation of a Novel Glycometabolism-Related Gene Signature Predicting Survival in Patients With Ovarian Cancer. Front Genet 11:585259. https://doi.org/10.3389/fgene.2020.585259

37. Zheng M, Mullikin H, Hester A et al. Development and Validation of a Novel 11-Gene Prognostic Model for Serous Ovarian Carcinomas Based on Lipid Metabolism Expression Profile. Int J Mol Sci (2020) 21:9169. https://doi.org/10.3390/ijms21239169

38. Qiu X, Guo D, Du J, Bai Y, Wang F. A novel biomarker, MRPS12 functions as a potential oncogene in ovarian cancer and is a promising prognostic candidate. Medicine. (2021) 100:e25898. https://doi.org/10.1097/MD.0000000000024898

\section{Figures}




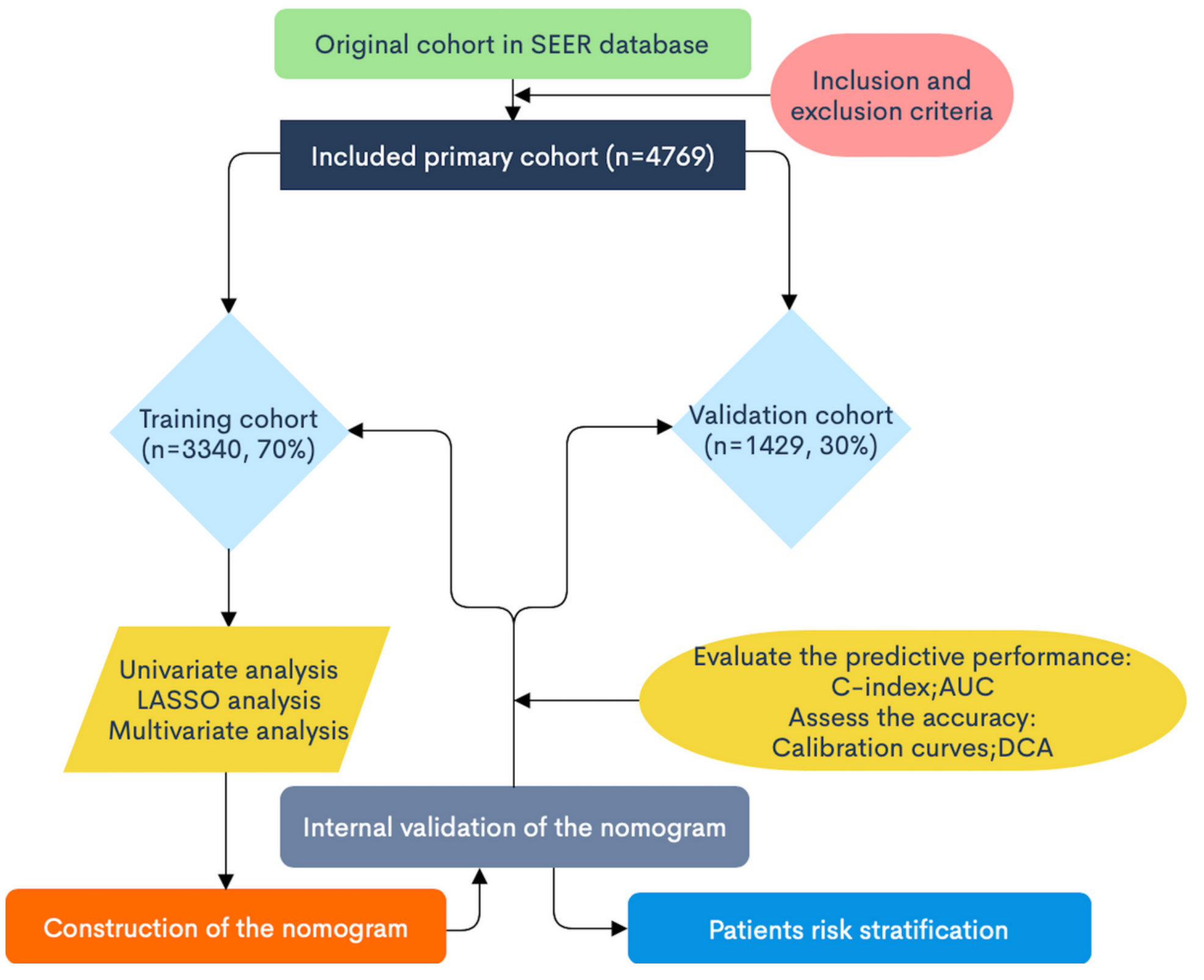

\section{Figure 1}

Patient selection flowchart. SEER: Surveillance, Epidemiology, and End Results. 
$\mathrm{a}$
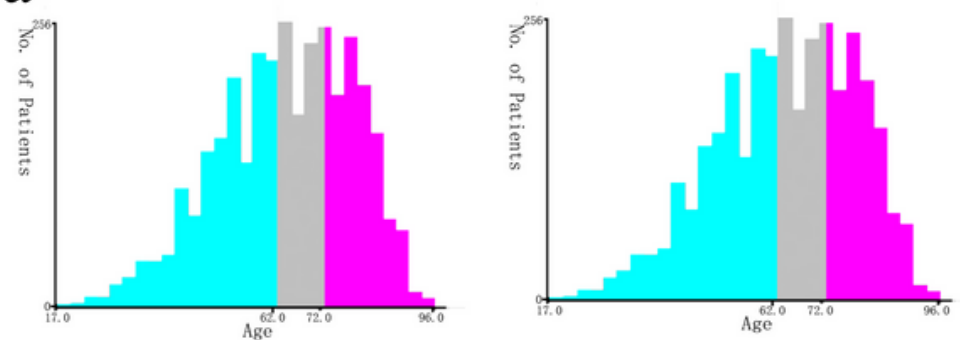

b
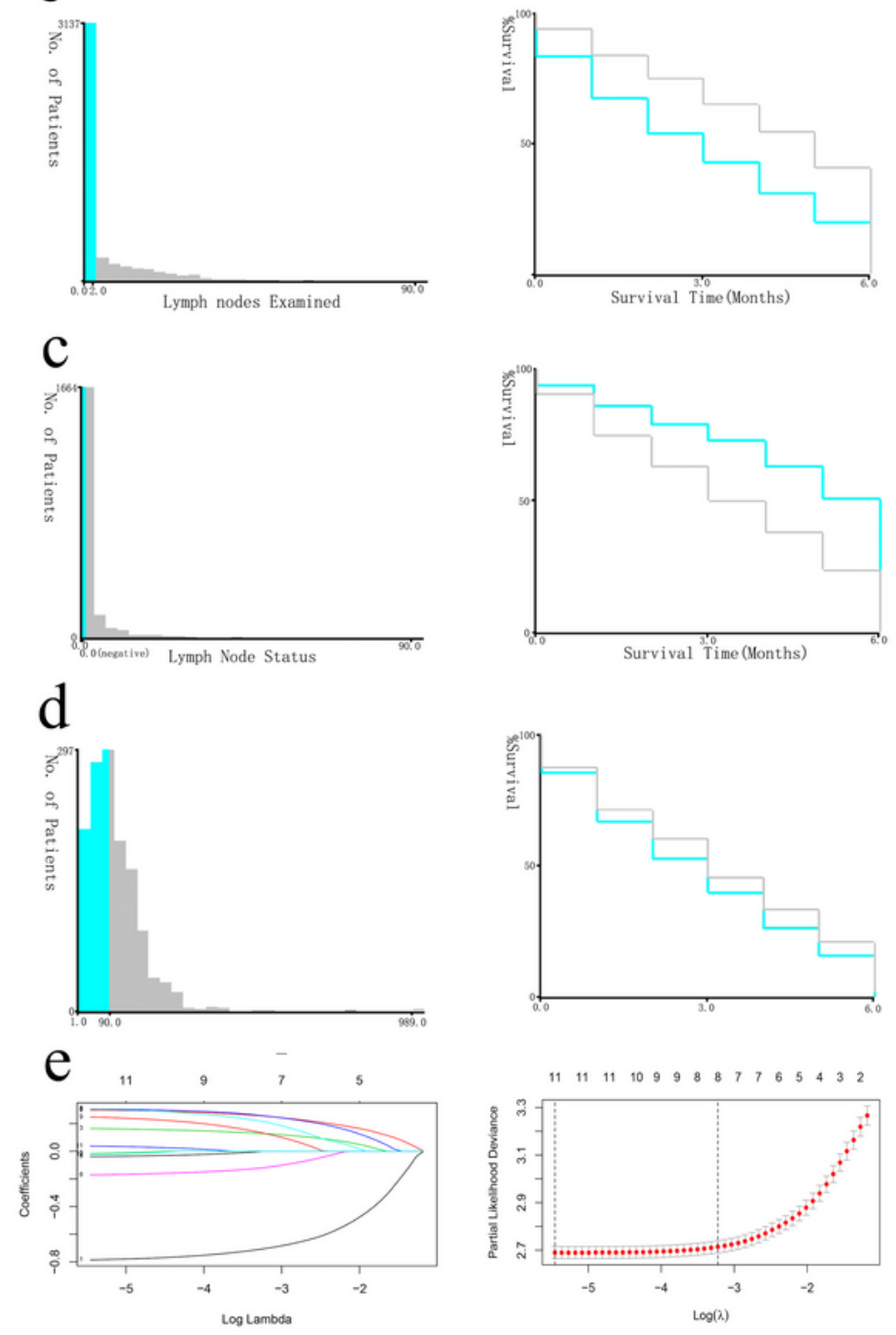

\section{Figure 2}

Cutoff values for age, lymph node examined, lymph node status, and tumor size which were assessed by X-tile analysis. (a) The appropriate cutoff values for age were 62 and 72 years old $(P<0.001)$. (b) The appropriate cutoff value for the number of lymph nodes examined was $2(P<0.001)$. (c) The appropriate cutoff value of lymph node status was positive or negative $(P<0.001)$. (d) The appropriate cutoff value 
for tumor size was $90 \mathrm{~mm}(\mathrm{P}<0.001)$. (e) LASSO regression identified 12 variables for CSS and LASSO Cox analysis identified 11 variables for CSS. CSS: cancer-specific survival.

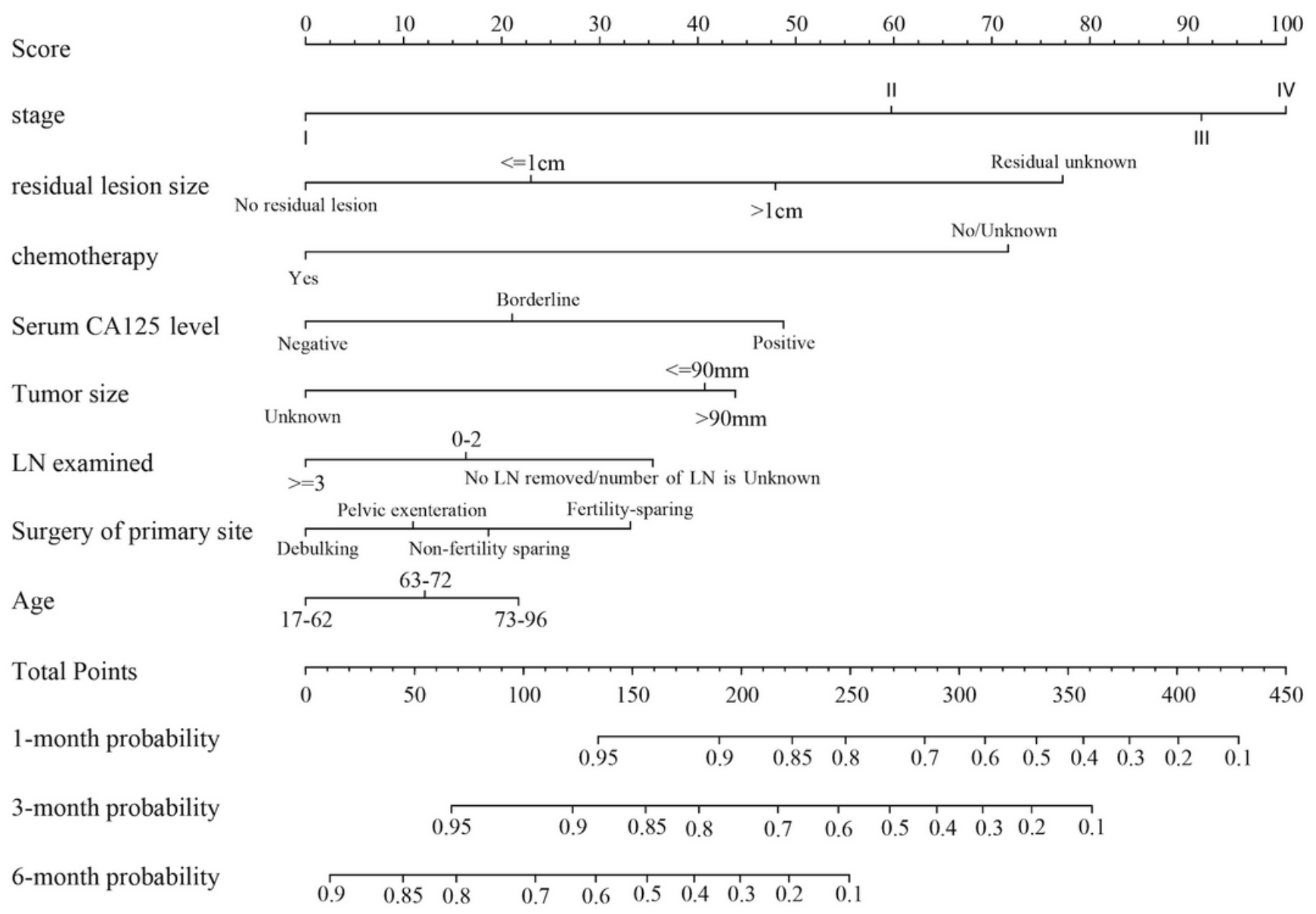

\section{Figure 3}

Nomogram for predicting 1-, 3-, and 5-year CSS. LN: lymph node; CSS: cancer-specific survival 

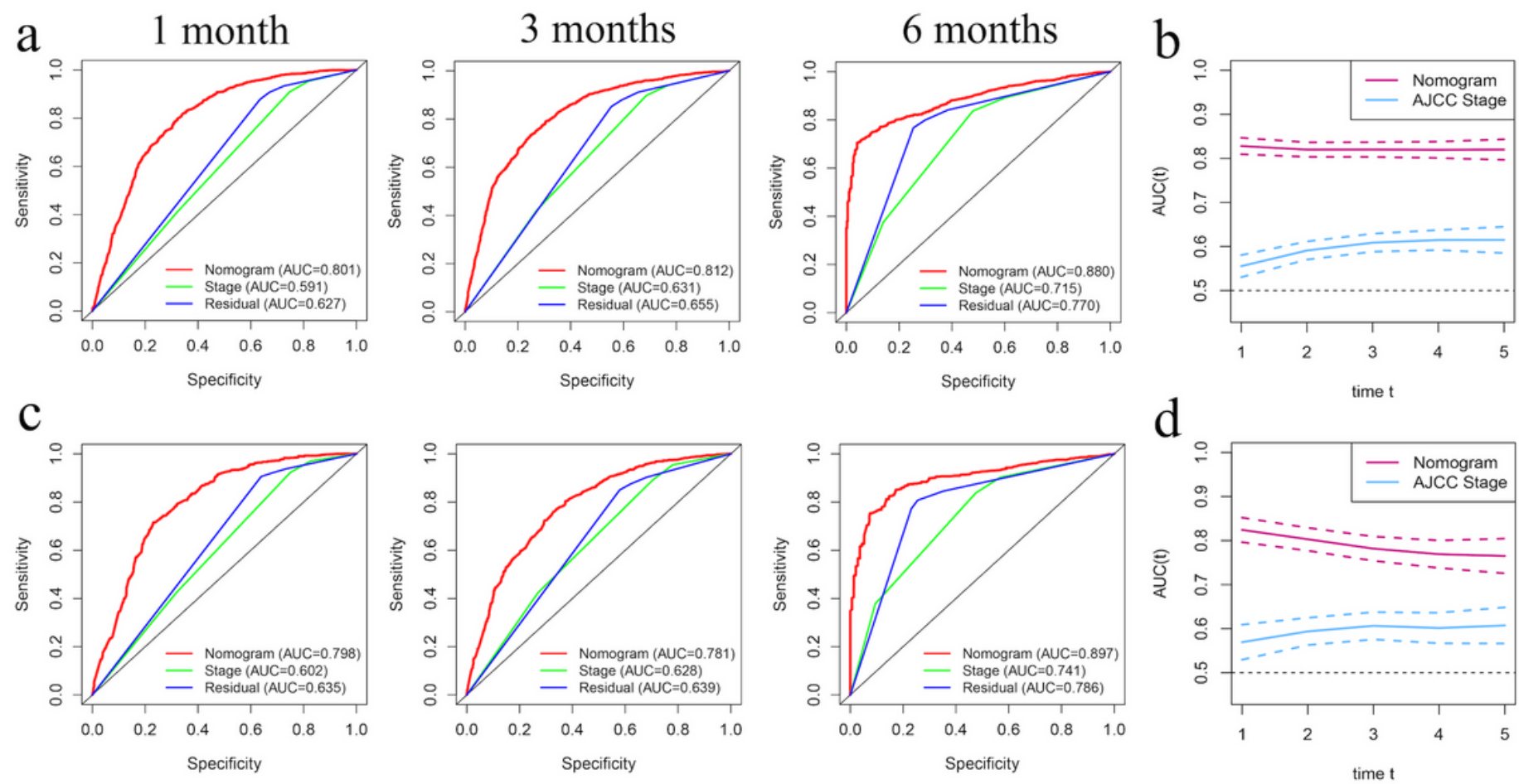

Figure 4

ROC curves for the nomogram, stage, and residual lesion size predictions of cancer-specific early death in the (a) training set and (c) validation set for 1-, 3-, and 6-month survival. Time dependence of the AUC for the nomogram and AJCC stage predictions of early death in the (b) training set and (d) validation set. AUC: area under the curve; ROC: receiver operating characteristic.

a

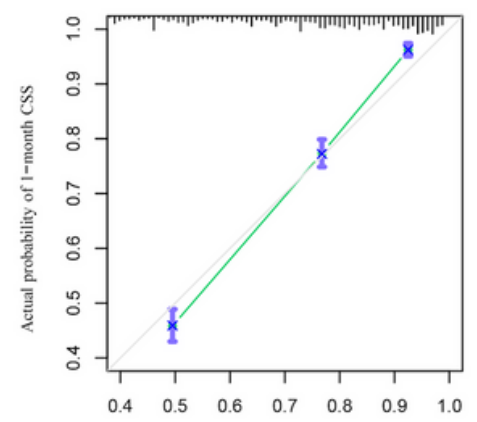

$\mathrm{b}$

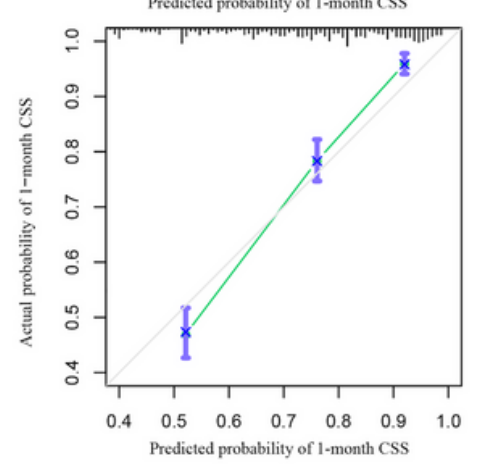

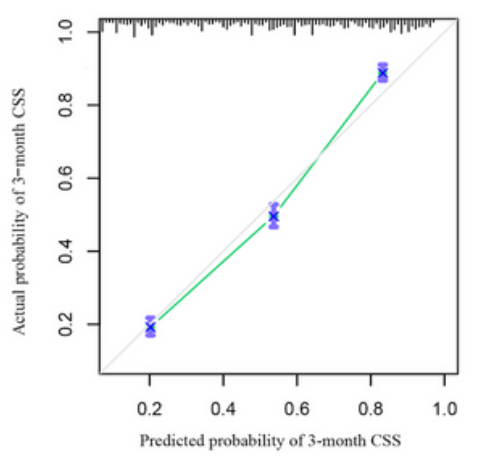

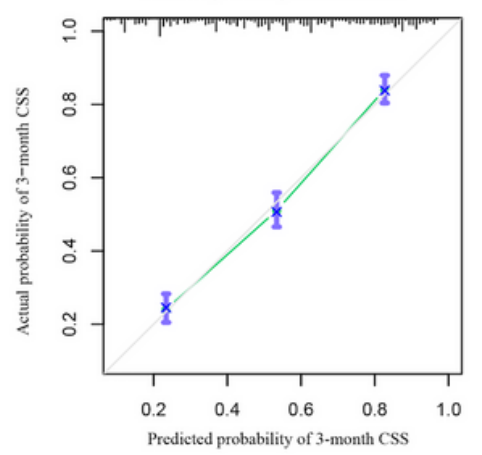

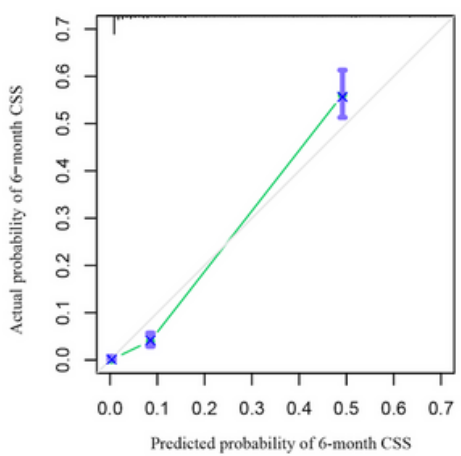

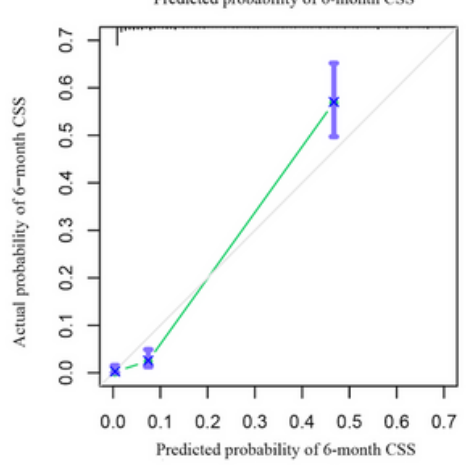

Figure 5 
Internal validation plots for evaluating nomogram calibration, at 1-, 3-, and 6-month cancer-specific survival (CSS). (a) Training set, 1-, 3-, and 6-months. (b) Validation set, 1-, 3-, and 6-months.
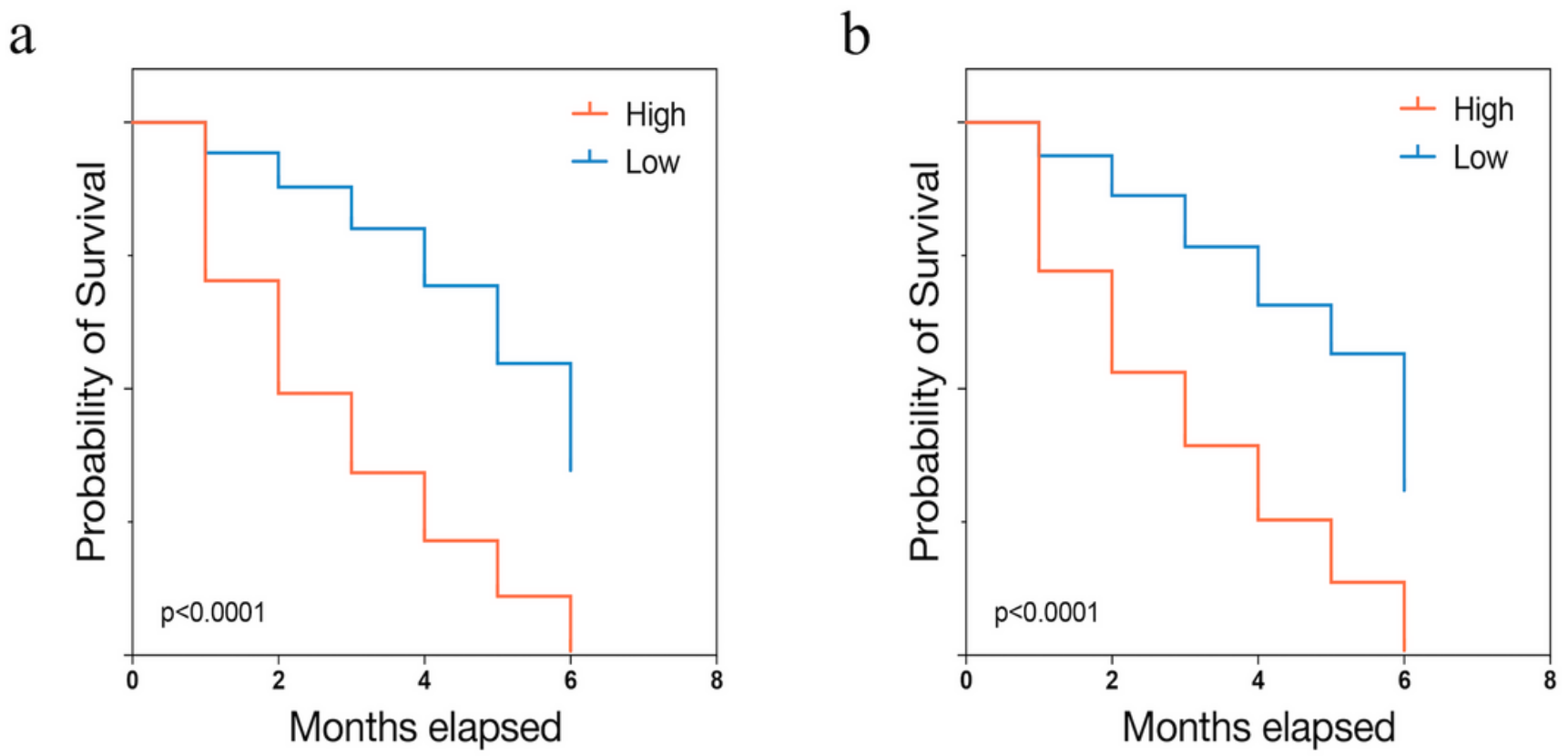

\section{Figure 6}

Kaplan-Meier curves showing cancer-specific survival of patients stratified by the risk stratification system. (a) Training set. (b) Validation set.

$\mathrm{a}$

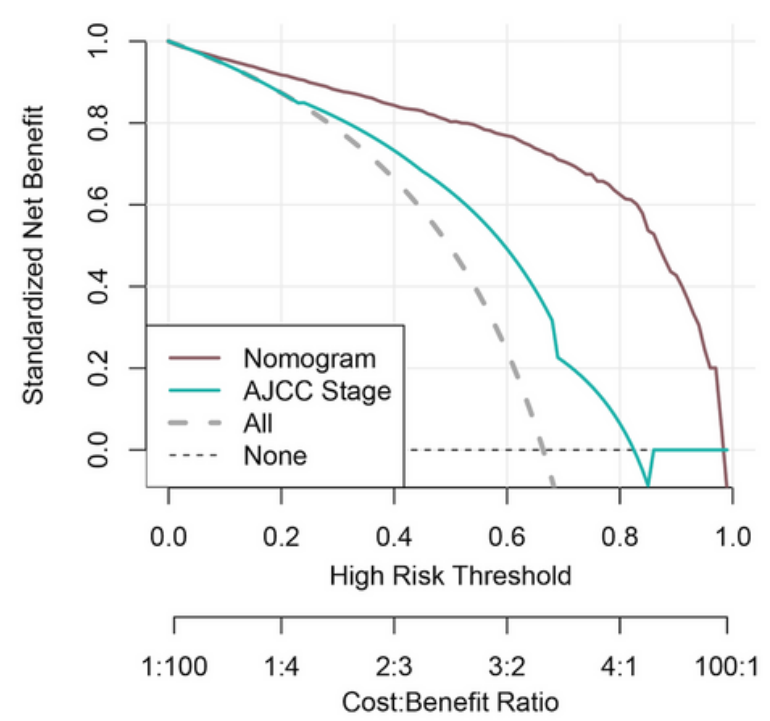

$\mathrm{b}$

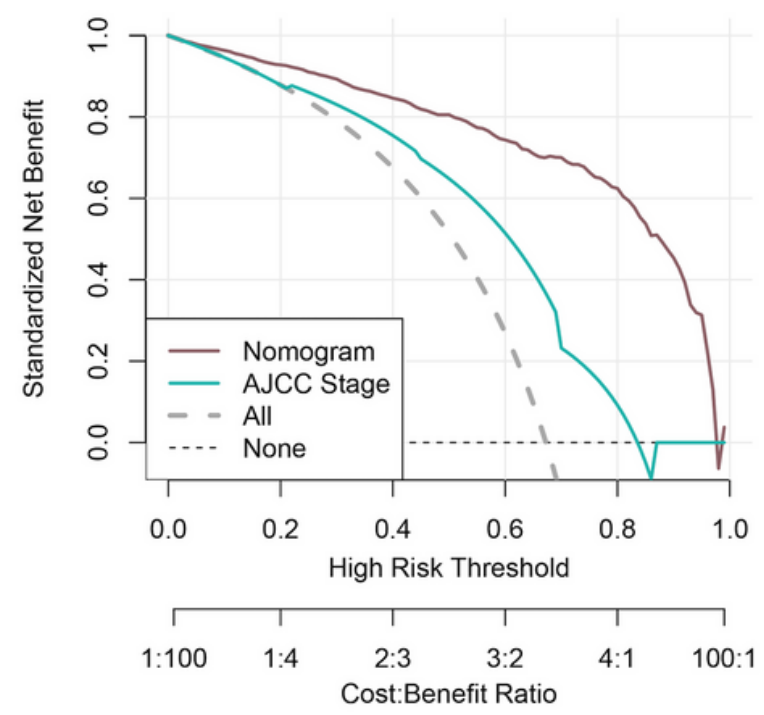

Figure 7 
Decision curve analysis of the early death predictions from the nomogram and the AJCC stage in the validation set. (a) Training set. (b) Validation set. 